Transportation Research Forum

Book Review: Assessing the Benefits of Transport

Book Author(s): European Conference of Ministers of Transport

Review Author(s): Brian Sloboda

Source: Journal of the Transportation Research Forum, Vol. 44, No. 3 (Fall 2005), pp. 163-164

Published by: Transportation Research Forum

Stable URL: http://www.trforum.org/journal

The Transportation Research Forum, founded in 1958, is an independent, nonprofit organization of transportation professionals who conduct, use, and benefit from research. Its purpose is to provide an impartial meeting ground for carriers, shippers, government officials, consultants, university researchers, suppliers, and others seeking exchange of information and ideas related to both passenger and freight transportation. More information on the Transportation Research Forum can be found on the Web at www.trforum.org. 


\section{Assessing the Benefits of Transport}

Assessing the Benefits of Transport is the report of a workshop in Bern, Switzerland, attended by the European Council of Ministers of Transport (ECMT). The theme of the report is the implementation of proper empirical assessments of transportation projects by incorporating the full economic costs and benefits using realistic assumptions and procedures. It asserts that all of the economic weaknesses, such as local monopoly pricing, must be properly incorporated into the empirical analysis, external environmental issues, and any unintended effects of transportation projects on the local labor markets. In recent years, European nations have been plagued by growing traffic, and the general response to this increased traffic has been to build more roads to accommodate more traffic. However, environmental regulations imposed by governments have stalled the construction of new roads, so any transportation projects would require a careful empirical assessment.

This report presents two empirical tools for the assessment of transportation projects: cost benefit analysis (CBA) and multi-criteria method (MCA). The CBA takes transportation projects and translates the costs and benefits into monetary values which are often based on subjective criteria. By allowing for this subjectivity, the transportation analyst can make an accurate determination of the value of the proposed project. In addition to the translation into monetary values, the transportation analyst would be able to determine the discount rate and the determination of the value of the benefits.

Accurate determination of benefits can be difficult, especially if parts of these are social benefits. The usual metrics for assessing benefits of transportation projects entails time savings, quality improvements, and others. However, the difficulty of these latter benefits is the lack of market prices for determining reasonable benefits. On the other hand, there are benefits which can easily be determined by assigning a market price to the benefit. The report further discusses the behaviors of imperfect competition on assessing transportation investments. In a perfectly competitive economy, a full CBA would capture all the economic impacts of a change to the transportation system. An economic benefit to a firm of workers being prepared to travel farther to work is another representation of the value of time-savings included in the CBA, not additional to these benefits. Where monopoly power is prevalent in transportation-related industries, firms will charge high prices needed to maximize profit. However, these prices will be higher than they should be to maximize economic welfare. In these circumstances, and provided prices in the transport sector reflect marginal social cost, a transport scheme which opens the area up to wider competition may bring prices down. Thus, additional economic activity will be generated. The result is benefits which are greater than the direct benefits as assessed by the CBA, pointing up the care analysts must exercise when calculating the benefits of transportationrelated projects.

The other empirical method is the multicriteria method (MCA) which acknowledges that not all aspects of transportation projects can be measured monetarily. That is, MCA provides indicators not measured in monetary terms but are instead often based on the quantitative analysis through scoring, ranking, and weighting of a wide range of criteria. MCA is applicable to cases where a single-criterion approach such as cost-benefit analysis falls short, especially where significant environmental and social impacts cannot be given monetary values because of the lack of market prices. 
MCA allows analysts to consider a full range of social, environmental, technical, economic, and financial criteria.

The ideal approach would be to incorporate the CBA and the MCA. Germany, France, Italy, and the United Kingdom currently use this combined approach; however, Belgium and the Netherlands continue to rely exclusively on the MCA. These two approaches are actually complementary, not mutually exclusive, alternatives. CBA should be used whenever there is a need to assess the benefits and costs of a proposed transportation project. In fact, transportation projects are often local projects, and policymakers could extend the results of CBA on a local level and apply them to a wider geographical area. Thus, the application of such results would not be accurate for the wider geographical area.

Under this condition, the objectivity of the transportation analysts would also be clouded by other considerations. As an example, transportation projects in the public sector that satisfy the CBA could be crowded out by private transportation projects that the politicians would consider more valuable. The private and public sectors have different criteria for determining the worthiness of transportation projects. Private transportation projects have market prices associated with them, while public-sector projects do not. How can the private and public-sector approaches be reconciled? A possible reconciliation would be to look at the opportunity cost rates, which France utilizes to assess its transportation projects. Finally, this report provides critical examinations of the assessment approaches of transportation projects in France, Germany, and the United Kingdom and includes a discussion of an approach to determining optimal levels of investment in transportation infrastructure for maximizing socio-economic welfare.

Thebookpresents an interesting comparison of the CBA and the MCA approaches for the assessment of transportation-related projects. A reader should keep in mind that travel is a derived demand and that rarely does the act of travel in itself produce a benefit to the traveler. Most often it involves a disbenefit in terms of cost and time. Usually the benefit of travel is a good or service obtained at the end of a trip. In the past, measuring economic benefits has been calculated by the changes in the cost of travel, but these benefits ignored the cost of the good or service acquired from the travel. A precise approach to measuring these benefits is to estimate the total transaction costs which sum the cost of the good and service as well as the cost of travel. This requires the estimation of prices of goods and services before and after the introduction of improvements in transportation infrastructure. Developing accurate metrics in CBA will allow for better information for policymakers to use. However, it should be kept in mind that the results of the CBA do not provide the complete analysis and that nonmonetary aspects provided by MCA must also be considered. Once policymakers have the monetary and nonmonetary metrics of a transportation-related project, policymakers will have the necessary information to determine the feasibility of projects.

\section{Brian Sloboda}

